\title{
Enhanced Oral Bioavailability of Astaxanthin with Droplet Size Reduction
}

\author{
M.M.R. Meor Mohd AfFandi ${ }^{1 *}$, T. Julianto ${ }^{1}$ and A.B.A. MajeEd ${ }^{1,2}$ \\ ${ }^{1}$ Department of Pharmaceutics, Faculty of Pharmacy, Universiti Teknologi MARA Malaysia, 42300 Puncak Alam, Selangor, Malaysia \\ ${ }^{2}$ Research Management Institute, Universiti Teknologi MARA Malaysia, 40450 Shah Alam, Selangor, Malaysia
}

Received January 27, 2012; Accepted March 21, 2012

\begin{abstract}
Astaxanthin is a natural xanthophyll abundantly found in Haematococcus pluvaris with strong antioxidant property and it is found to be useful in many biological functions. Recent scientific findings indicate that astaxanthin shows low oral bioavailability due to its lipophilicity. However, the influence of emulsion droplet size on astaxanthin bioavailability is yet to be studied. This study was performed to investigate the effects of emulsion droplet size reduction on the bioavailability of astaxanthin emulsion through oral administration. In vivo study was carried out to evaluate the rate and extent of absorption of macro and nanosized emulsion an oil solution formulation. The nanosized emulsion shows increased $\mathrm{C}_{\max }$ and $\mathrm{AUC}_{0-\infty}$ and decreased $\mathrm{T}_{\max }$ values with a reduction of the emulsion globule size. The $\mathrm{AUC}_{0-\infty}$ of nanosized compared to macrosized emulsion and oil solution was increased by $110 \%-140 \%$ and $140 \%-200 \%$ respectively.
\end{abstract}

Keywords: astaxanthin, bioavailability, droplet size reduction

\section{Introduction}

Astaxanthin is a naturally occurring carotenoid that belongs to the xanthophyll group with excellent antioxidant properties. Astaxanthin is de novo synthesized by bacterium belonging to genus Paracoccus, yeast (Xanthophyllomyces dendrorhous), green algae (Haematococcuspluvaris and Chlamydomonasnivalis) and Adonis plants (Goswami et al., 2010). Astaxanthin is also found in crustaceans, salmon and trout (Kurashige et al., 1990; Clark et al., 2000). They accumulate astaxanthin through the food chain and metabolic conversion. Recent scientific findings indicate that astaxanthin showed quenching activity for singlet oxygen and inhibition of lipid peroxidation compared to $\beta$-carotene and vitamin $\mathrm{E}$ by 40 and 1000 times, respectively (Kurashige et al., 1990; Shimidzu 1996). It has been found to provide many essential biological functions, such as protection against lipid-membrane peroxidation of essential polyunsaturated fatty acids and proteins, DNA damage and ultra violet light effects. It also plays an important role in immunological defence and prevention of age-related macular degeneration (AMD) (Martin et al., 2003).

Animals lack the ability to synthesize the carotenoids

*To whom correspondence should be addressed.

E-mail: meor@salam.uitm.edu.my de novo, and can be supplied with carotenoids, that are biosynthesized by microorganisms or by algae and plants, through their dietary intake (Olaizola and Huntly, 2003). Commercially astaxanthin is produced from both synthetic and natural sources. The primary and abundant natural source of astaxanthin for commercial uses is microalgae Haematococuc pluvialis. It synthesizes astaxanthin from the carotenoids, lycopene or phytoene when exposed to extreme environmental conditions and ultraviolet light (Lorenz and Cysewski, 2000).

Astaxanthin like other carotenoids is very lipophilic compound which recorded low oral bioavailability. It varies from less than $10 \%$ for raw uncooked vegetables to more than $50 \%$ in oily solutions or in synthetic commercial formulations (Olson, 1994). As a fat soluble material, astaxanthin follows the same intestinal absorption path as dietary fat. Astaxanthin absorption involves several steps from the breakdown of the food matrix to the release of astaxanthin into the lumen of the gastrointestinal tract (GIT) through their incorporation into lymphatic lipoproteins (Furr and Clark, 1997). This includes mechanical and chemical disruption of the food matrix, dispersion in lipid emulsion particles, solubilization into mixed bile salt micelles, movement across the unstirred water layer adjacent to the microvilli, uptake by the enterocyte, and incorporation into lymphatic lipoproteins 
(Furr and Clark, 1997). Any disruption at any point along this chain contributes to low absorption of astaxanthin.

Thus far, very limited information is available concerning the improvement of astaxanthin oral bioavailability. Most of the studies were focused on improvements of the carotenoid such as $\beta$-carotene. These include studies on oilin-water emulsions (Amar et al., 2003), nanodispersions (Tan and Nakajima, 2005) and oil-in-water nanoemulsions (Yuan et al., 2008). These studies show an impressive result in improving $\beta$-carotene bioavailability. The only research done so far on the improvement of astaxanthin bioavailability was performed by Odeberg et al. (2003), who proved that the bioavailability of astaxanthin could been increased by incorporating the drug into an emulsion form. This positive result was attributed to the presence of surfactants in the emulsion, which increases the surface area for the release of astaxanthin from the vehicle. Emulsion itself also mimics the formation of bile salt micelles (which are formed during lipolysis and facilitate absorption of lipophilic compounds) and thereby increases the solubility of astaxanthin (Odeberg et al., 2003).

By formulating astaxanthin in the emulsion form, which is considered as lipid-based formulation, there is a high chance for the drug to gain access to the systemic circulation via lymphatic route which can avoid hepatic first-pass metabolism. As a continuous improvement from the studies done by Odeberg et al. (2003), it has become an interest to us to investigate the influence of emulsion droplet size on the bioavailability of astaxanthin.

\section{Materials and Methods}

Materials Astareal extract 10FC grade (an oil extract containing $10 \% \mathrm{w} / \mathrm{w}$ of standardized astaxanthin derived from Haematococcus pluvialis) was purchased from Fuji Chemical Industry (Nakaniikawa, Toyama, Japan) Industry (Nakaniikawa, Toyama, Japan), lecithin (L- $\alpha-$ phosphatidylcholine, Type IV-S $\geq 30 \%$ TLC (thin layer chromatography) - P3644) was puchased from Sigma (St Louis, Missouri, USA) while Tween 80 (polyoxyethylene (20) sorbitan monooleate) was purchased from Zulat Pharmacy (Selangor, Malaysia). Pure palm olein was purchased from FFM Berhad (Selangor, Malaysia). The water used was obtained from Elga Pure Lab (Marlow Buck, UK) water system. All other chemicals used were of analytical grade unless otherwise stated.

\section{Methods}

1) Preparation of astaxanthin oil formulation Astaxanthin oil (which contained $2 \% \mathrm{w} / \mathrm{w}$ of standardized astaxanthin) was prepared by diluting astaxanthin extract $10 \mathrm{FC}$ grade in pure palm olein. The mixture was then mixed ho- mogeneously for $5 \mathrm{~min}$ at $50 \mathrm{rpm}$. This formulation was used as the base of the emulsion and reference formulation of this study.

\section{2) Preparation of astaxanthin emulsion formulation} Astaxanthin emulsion was formulated as per method developed by Meor Mohd Affandi et al. (2011). Astaxanthin oil (16\%) was mixed with purified water $(80 \% \mathrm{w} / \mathrm{w})$ containing Tween 80 and lecithin as the emulsifier (4\% w/w). To produce macro sized emulsion, the premix was homogenised by High Speed Homogeniser (HSH) (Silverson Homogeniser, UK) at $9000 \mathrm{rpm}$ for $5 \mathrm{~min}$ to give oil droplet average size of $8.9 \mu \mathrm{m}$. Nanosized emulsion was produced by further homogenization of macrosized emulsion with High Pressure Homogeniser (HPH) (model APV 1000, APV Systems, Albertsland, Denmark) at 800 bar for 5 cycles. Astaxanthin oil preparation was used as the reference formulation of this study. Table 1 simplified the ratio of component and treatment used in each of the formulations.

3) Bioavailability study protocol All experiments were performed according to Universiti Teknologi MARA (UiTM) guidelines of experimental animal care and approved by UiTM Animal Research and Ethics Commitee. Male Sprague-Dawley rats weighing approximately $200 \mathrm{~g}$ were used. The rats were maintained at controlled temperature and relative humidity on a 12 -hour light-dark cycle. They were fasted for $12 \mathrm{~h}$ before formulation administration and for $3 \mathrm{~h}$ after dosing. This study was a cross-over study and the rats were divided into 3 groups of 3 rats each, to which all the 3 different formulations were given orally. The washout period of one week between each treatment was implemented (Table 2). Water was freely available throughout the duration of the experiments.

Blood sampling Blood samples were taken from the tail at $0,1,2,3,4,6,8,10,12,24,48$ and $72 \mathrm{~h}$. All samples were collected in $5 \mathrm{~mL}$ heparin tubes and were centrifuged at $14000 \mathrm{rpm}$ for $20 \mathrm{~min}$. Plasma separated was transferred into the eppendof microcentrifuge tube and stored at $-20^{\circ} \mathrm{C}$ until further analysis.

Analytical method Analysis of astaxanthin was performed using direct injection method with simple deproteinizing process developed by Meor Mohd Affandi et al. (2012). The detector was operated at a wavelengh of $474 \mathrm{~nm}$. A Phenomenex HPLC column from Phenomenex, USA fitted with synergi $4 \mu \mathrm{m}$ Hydro-RP 80A $(150 \times 4.6 \mathrm{~mm})$ and a refillable guard column (Phenomenex, USA) was used for the chromatographic separation. The mobile phase comprised methanol:water:ethyl acetate (82:8:10 (v/v)). Analysis was run at a flow rate of $1.5 \mathrm{~mL} / \mathrm{min}$ and the samples quantified using area under the curve (AUC) by isocratic mode.

Plasma sample and control plasma ware thawed at room 
Table 1. Astaxanthin formulations : Ratio of component and treatment used in each of the different formulations.

\begin{tabular}{|c|c|c|c|c|c|c|c|}
\hline Formulation & $\begin{array}{c}\text { Astaxanthin } \\
\text { Extract }\end{array}$ & Palm Olein & Water & $\begin{array}{c}\text { Surfactant } \\
\text { (Tween } 80+\text { Lecithin) }\end{array}$ & $\begin{array}{l}\text { High Speed } \\
\text { Homogeniser } \\
\quad(\mathrm{HSH})\end{array}$ & $\begin{array}{l}\text { High Pressure } \\
\text { Homogeniser } \\
(\mathrm{HPH})\end{array}$ & $\begin{array}{l}\text { Droplet size } \\
\quad(\mu \mathrm{m})\end{array}$ \\
\hline $\begin{array}{l}\text { Reference } \\
\text { (Astaxanthin Oil) }\end{array}$ & $2 \%$ & $98 \%$ & - & - & - & - & - \\
\hline $\begin{array}{l}\text { A } \\
\text { (macrosized emulsion) }\end{array}$ & $2 \%$ & $14 \%$ & $80 \%$ & $4 \%$ & $\begin{array}{l}9000 \mathrm{rpm} \\
5 \mathrm{~min}\end{array}$ & - & $8.9 \pm 0.014$ \\
\hline $\begin{array}{l}\text { B } \\
\text { (nanosized emulsion) }\end{array}$ & $2 \%$ & $14 \%$ & $80 \%$ & $4 \%$ & $\begin{array}{l}9000 \mathrm{rpm} \\
5 \mathrm{~min}\end{array}$ & $\begin{array}{l}800 \text { bar } \\
5 \text { cycles }\end{array}$ & $0.128 \pm 0.015$ \\
\hline
\end{tabular}

Table 2. Three-way cross over design schedule with 3 rats in each group.

\begin{tabular}{cccc}
\hline Group & \multicolumn{3}{c}{ Week } \\
\cline { 2 - 4 } (3 rats / group) & 1st & 2nd & 3rd \\
\hline 1 & A & B & C \\
2 & B & C & A \\
3 & C & A & B \\
\hline
\end{tabular}

\section{A : Oil formulation $\quad$ B : Macrosized emulsion}

C: Nanosized emulsion

temperature under minimal exposure to light. The plasma was then treated using the following procedure: $100 \mu \mathrm{L}$ plasma was measured into an eppendorf microcentrifuge and deproteinised using $200 \mu \mathrm{L}$ of mixture of ethanol and tetrahydrofuran (1:9). The mixture was vortexed for 2 min using a vortex mixer and centrifuged at $14000 \mathrm{rpm}$ for $20 \mathrm{~min}$ (Eppendorf, USA). After centrifugation, a $50 \mu \mathrm{L}$ of the clear supernatant was then injected into the HPLC system. The astaxanthin was eluted using an isocratic gradient with methanol:water:ethyl acetate $(82: 8: 10)$ as a mobile phase. Astaxanthin was detected at $474 \mathrm{~nm}$ and was eluted at $4.1 \mathrm{~min}$.

Pharmacokinetics calculations The following kinetic parameters were estimated for astaxanthin: $\mathrm{C}_{\max }$ (maximum observed plasma concentration), $\mathrm{T}_{\max }$ (the time to reach maximum concentration), $\mathrm{AUC}_{0-\infty}$ (area under the curve calculated to infinity which reflects the total amount of drug that reaches the systemic circulation) and $t_{1 / 2}$ (elimination halflife). $C_{\max }, T_{\max }$, and $t_{1 / 2}$ were read directly from the observed concentration versus time data. A linear-log trapezoidal method was used when calculating $\mathrm{AUC}_{0-\infty}$.

Statistical analysis In this experiment, assumption was made that $\mathrm{C}_{\max }, \mathrm{t}_{1 / 2}$ and $\mathrm{AUC}_{0-\infty}$ for astaxanthin, estimated to be normally distributed when log transformed. In order to achieve the primary objective of this study which is to find formulations which were superior, a comparison of means was made between groups using one-way ANOVA followed by Student's t-test, with $95 \%$ confidence interval. Statisti- cal analyses were carried out using the SPSS version 17.0. The whole data collection on in drug formulation experiment were done at least in triplicate.

\section{Results and Discussion}

In order to investigate the effects of different lipid based formulations and droplet size emulsion formulations on the bioavailability of astaxanthin after oral administration, the macro and nanosized emulsion formulations were given orally to the rats and astaxanthin in oil was used as reference. The plasma profiles of astaxanthin in adult Sprague Dawley rats following oral administration of macrosized emulsion, nanosize emulsion and oil solution of astaxanthin were compared.

It is clearly presented in Figure 1 that astaxanthin administered in macrosized and nanosized emulsion represents significantly greater improvement of drug absorption than astaxanthin in oil. This result agrees with the findings of Odeberg et al. (2003) who reported that the absorption of astaxanthin can be enhanced when surfactants with the right combination of lipophilic and hydrophilic are added in the formulation. As also presented in Figure 1, astaxanthin administered in nanosize shows the highest astaxanthin plasma concentration followed by the macrosized emulsion and oil solution.

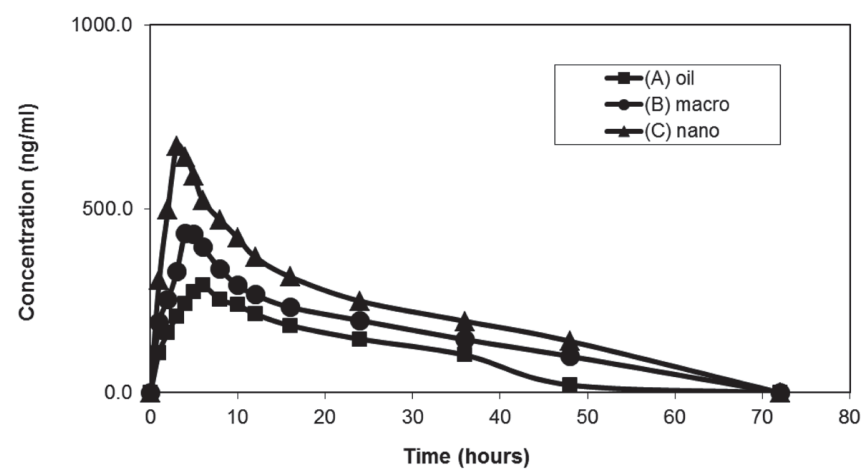

Fig. 1. Rat plasma concentration versus time profile of nanosized emulsion, macrosized emulsion and oil solution of astaxanthin after oral administration of $80 \mathrm{mg} / \mathrm{kg}$ astaxanthin formulation $(\mathrm{n}=9)$. 
Effects of Emulsion droplet size on astaxanthin bioavailability Different types of lipid based formulations play an important role in enhancing the absorption of astaxanthin (Odeberg et al., 2003). Both emulsion formulations, namely nanosize and macrosize show a significant increase in astaxanthin absorption compared to oil solution. Thus far, studies on astaxanthin have only focused on the effects of lipid based formulations on astaxanthin absorption (Odeberg et al., 2003). Therefore, it has become an interest to study the effects of emulsion droplet size on astaxanthin bioavailability.

Effects of emulsion droplet size in $C_{\max }, A U C_{0-\infty}$ and $T_{\max }$ As presented in Figure 1, astaxanthin administered in nanosize shows the highest astaxanthin plasma concentration followed by the macrosized emulsion and oil solution. As shown further in Table 3, decreasing the emulsion droplet size resulted in significant increase in $\mathrm{C}_{\max }$. Nanosized astaxanthin emulsion mean $\mathrm{C}_{\max }$ was $698.7 \pm 38.7 \mathrm{ng} / \mathrm{mL}$, compared to that of macrosized astaxanthin emulsion which was $465.1 \pm 43.0 \mathrm{ng} / \mathrm{mL}$ and oil solution which was $313.3 \pm$ $12.9 \mathrm{ng} / \mathrm{mL}$. Statistically, the difference in mean $\mathrm{C}_{\max }$ values, were significant $(\mathrm{P}<0.05)$ when the nanosize emulsions were compared to the macrosize astaxanthin emulsions and astaxanthin oil solution. The $95 \%$ confidence interval of the logarithmic transformed $\mathrm{C}_{\max }$ value of nanosized astaxanthin emulsion over those of macrosized emulsion and oil solution was found to lie between 1.4 to 1.5 and 2.1 to 2.4 , respectively.

It was also observed that the decreasing of emulsion droplet size resulted in a significant increase in $\mathrm{AUC}_{0-\infty}$.
The mean value of $\mathrm{AUC}_{0-\infty}$ nanosized astaxanthin emulsion was $20625 \pm 5072 \mathrm{~h} . \mathrm{ng} / \mathrm{mL}$ compared to those of macrosize astaxanthin emulsion which was $15859 \pm 1682 \mathrm{~h} . \mathrm{ng} / \mathrm{mL}$ and oil solution which was $11484 \pm 2412$ h.ng/mL. Statistically, the difference in $\mathrm{AUC}_{0-\infty}$ of nanosized astaxanthin emulsion was significant $(\mathrm{P}<0.05)$ when compared to $\mathrm{AUC}_{0_{-} \infty}$ of macrosized astaxanthin emulsion and astaxanthin oil solution. The 95\% confidence interval of the logarithmic transformed $\mathrm{AUC}_{0-\infty}$ value of nanosized astaxanthin emulsion over those of macrosized emulsion and oil solution was found to lie between 1.0 to 1.4 and 1.4 to 2.0 , respectively.

The significant increase of $\mathrm{C}_{\max }$ and $\mathrm{AUC}_{0-\infty}$ by the decreasing of emulsion droplet size clearly shows that the absorption of astaxanthin can be enhanced when the emulsion droplet size is reduced. Smaller oil droplet size will increase the surface area of the drug and improve its solubility behaviour as well as its permeation. Moreover, smaller oil droplet size will not delay gastric emptying time and this will result in faster drug absorption. These statements are in agreement with the $T_{\max }$ values which are reduced with the decrease of emulsion droplet size. Nanosized emulsion achieved the shortest $\mathrm{T}_{\max }$ which was $2.8 \pm 0.73 \mathrm{~h}$ followed by macrosized emulsion $(4.3 \pm 0.50 \mathrm{~h})$ and oil solution $(5.5 \pm 0.66 \mathrm{~h})$. Statistically, the difference in $\mathrm{T}_{\max }$ of nanosized astaxanthin emulsion, is significant $(\mathrm{P}<0.05)$ when compared to $\mathrm{T}_{\max }$ value of macrosized astaxanthin emulsion and oil solution.

Effects of emulsion droplet size on $K_{e}$ and $t_{1 / 2} \quad$ Table 4 indicates that the $\mathrm{K}_{\mathrm{e}}$ and $\mathrm{t}_{1 / 2}$ of three different sizes of emulsion oil droplet. The drug elimination for all formulations follow the first order kinetics where drug decreases exponen-

Table 3. Individual numerical value of $\mathrm{C}_{\max }, \mathrm{T}_{\max }$ and $\mathrm{AUC}_{0-\infty}$. of three types of formulation tested on nine.

\begin{tabular}{|c|c|c|c|c|c|c|c|c|c|}
\hline \multirow{2}{*}{ Subject } & \multicolumn{3}{|c|}{ Oil Solution } & \multicolumn{3}{|c|}{ Macrosized emulsion } & \multicolumn{3}{|c|}{ Nanosized emulsion } \\
\hline & $\begin{array}{c}\mathrm{C}_{\max } \\
(\mathrm{ng} / \mathrm{mL})\end{array}$ & $\begin{array}{l}\mathrm{T}_{\max } \\
(\mathrm{h})\end{array}$ & $\begin{array}{l}\mathrm{AUC}_{0-\infty} \\
\text { (h.ng.mL) }\end{array}$ & $\begin{array}{c}\mathrm{C}_{\max } \\
(\mathrm{ng} / \mathrm{mL})\end{array}$ & $\begin{array}{l}\mathrm{T}_{\max } \\
(\mathrm{h})\end{array}$ & $\begin{array}{l}\mathrm{AUC}_{0-\infty} \\
\text { (h.ng.mL) }\end{array}$ & $\begin{array}{c}\mathrm{C}_{\max } \\
(\mathrm{ng} / \mathrm{mL})\end{array}$ & $\begin{array}{l}\mathrm{T}_{\max } \\
(\mathrm{h})\end{array}$ & $\begin{array}{l}\mathrm{AUC}_{0-\infty} \\
\text { (h.ng.mL) }\end{array}$ \\
\hline 1 & 325.08 & 5.0 & 11302.83 & 499.60 & 4.0 & 17719.50 & 697.08 & 3.0 & 20730.78 \\
\hline 2 & 330.16 & 4.0 & 13563.82 & 429.55 & 4.0 & 16587.34 & 653.33 & 2.0 & 25505.29 \\
\hline 3 & 315.76 & 5.0 & 6804.70 & 429.55 & 4.0 & 12349.32 & 640.84 & 2.0 & 24732.22 \\
\hline 4 & 311.61 & 5.0 & 11037.66 & 403.74 & 4.0 & 14214.22 & 732.93 & 3.0 & 13251.19 \\
\hline 5 & 309.40 & 6.0 & 14204.42 & 437.39 & 5.0 & 15137.53 & 682.69 & 4.0 & 15671.24 \\
\hline 6 & 294.92 & 6.0 & 10702.20 & 497.28 & 4.0 & 16201.53 & 746.32 & 3.0 & 16383.32 \\
\hline 7 & 330.01 & 6.0 & 10910.69 & 459.73 & 5.0 & 16977.00 & 694.47 & 3.0 & 26937.56 \\
\hline 8 & 301.36 & 6.0 & 14656.05 & 531.82 & 4.0 & 16587.53 & 751.51 & 2.0 & 24931.84 \\
\hline 9 & 301.91 & 6.0 & 10175.88 & 497.22 & 5.0 & 16961.73 & 689.22 & 3.0 & 17482.05 \\
\hline Mean & 313.36 & 5.4 & 11484.25 & 465.10 & 4.3 & 15859.52 & 698.71 & 2.8 & 20625.05 \\
\hline SD & 12.924 & 0.667 & 2412.654 & 43.008 & 0.5 & 1682.619 & 38.733 & 0.726 & 5072.939 \\
\hline $\mathrm{CV} \%$ & 4.1 & 12.4 & 21.0 & 9.2 & 11.6 & 10.6 & 5.5 & 25.9 & 24.60 \\
\hline
\end{tabular}

CV: Coefficient of variation, SD: Standard Deviation 
Table 4. Individual numerical value of $t_{1 / 2}$ and $\mathrm{Ke}$ of three types of formulation tested on nine.

\begin{tabular}{|c|c|c|c|c|c|c|}
\hline \multirow{2}{*}{ Subject } & \multicolumn{2}{|c|}{ Oil Solution } & \multicolumn{2}{|c|}{ Macrosized emulsion } & \multicolumn{2}{|c|}{ Nanosized emulsion } \\
\hline & $\mathrm{K}_{\mathrm{e}}\left(\mathrm{h}^{-1}\right)$ & $\mathrm{t}_{1 / 2}(\mathrm{~h})$ & $\mathrm{K}_{\mathrm{e}}\left(\mathrm{h}^{-1}\right)$ & $t_{1 / 2}(h)$ & $\mathrm{K}_{\mathrm{e}}\left(\mathrm{h}^{-1}\right)$ & $\mathrm{t}_{1 / 2}(\mathrm{~h})$ \\
\hline 1 & 0.0268 & 25.9 & 0.023 & 30.7 & 0.022 & 31.4 \\
\hline 2 & 0.0257 & 27.0 & 0.035 & 20.1 & 0.022 & 31.3 \\
\hline 3 & 0.0569 & 12.2 & 0.029 & 23.8 & 0.024 & 28.5 \\
\hline 4 & 0.0255 & 27.2 & 0.022 & 31.9 & 0.021 & 33.1 \\
\hline 5 & 0.0226 & 30.7 & 0.019 & 37.0 & 0.031 & 22.7 \\
\hline 6 & 0.0207 & 33.5 & 0.026 & 26.6 & 0.033 & 20.9 \\
\hline 7 & 0.0328 & 21.2 & 0.019 & 35.9 & 0.015 & 46.5 \\
\hline 8 & 0.0208 & 33.4 & 0.023 & 30.7 & 0.021 & 33.2 \\
\hline 9 & 0.0210 & 33.0 & 0.024 & 29.1 & 0.029 & 23.6 \\
\hline Mean & 0.0281 & 27.1 & 0.024 & 29.5 & 0.024 & 30.1 \\
\hline SD & 0.01147 & 6.95876 & 0.00499 & 5.43425 & 0.00576 & 7.723903 \\
\hline CV\% & 40.8 & 25.7 & 20.5 & 18.4 & 23.7 & 25.67 \\
\hline
\end{tabular}

CV: Coefficient of variation, SD: Standard Deviation

tially with time and $\mathrm{t}_{1 / 2}$ was recorded at $30.1 \pm 7.7 \mathrm{~h}, 29.5 \pm$ $5.4 \mathrm{~h}$ and $27.1 \pm 6.9 \mathrm{~h}$ for nanosized emulsion, macrosized emulsion and oil solution, respectively. These results did not deviate much from the previous published studies regarding the pharmacokinetics of astaxanthin, which reported the half-lives at $21 \pm 11 \mathrm{~h}$ (Osterlie et al., 2000) and $15.9 \pm 5.3 \mathrm{~h}$ (Odeberg et al., 2003). The results also show that the size of emulsion globule does not influence $\mathrm{K}_{\mathrm{e}}$ and $\mathrm{t}_{1 / 2}$ value.

\section{Conclusion}

This study confirmed that the bioavailability of astaxanthin could be enhanced in rats with the reduction of oil droplet size. The nanosized emulsion shows a significant increase in $\mathrm{C}_{\max }$ and $\mathrm{AUC}_{0-\infty}$ value followed by macrosized emulsion and oil solution. Conversely the $\mathrm{T}_{\max }$ value was reduced with the reduction of emulsion globule size. The kinetics of astaxanthin is described as a one-compartment model with a halflife of $29.7 \pm 7.4 \mathrm{~h}, 28.9 \pm 5.4 \mathrm{~h}$ and $27.5 \pm 6.6 \mathrm{~h}$ for nanosized and macrosized emulsion and oil solution, respectively. In this present study, we focused on the bioavailability improvement of astaxanthin by using rats as a subject. Since the usage and application of astaxanthin for human consumption has emerged in the past few years in the nutraceutical field, it is becoming interesting to investigate the performance of the astaxanthin nanoemulsion formulated in this study on human subjects.

Acknowledgement The authors will like to thank Faculty of Pharmacy Universiti Teknologi MARA, Puncak Alam Campus for the financial support.

\section{References}

Amar, I., Aserin, A. and Garti, N. (2003). Solubilization patterns of lutein and lutein esters in food grade non-ionic microemulsions. $J$. Agr. Food Chem., 51, 4775-4781.

Clark, R.M., Yao, L., She, L. and Furr, H.C. (2000). A comparison of lycopene and astaxanthin absorption from corn oil and olive oil emulsions. Lipids, 35, 803-806.

Furr, H.C. and Clark, R.M. (1997). Intestinal absorption and tissue distribution of carotenoids. J. Nutr. Biochem., 8, 364-377.

Goswami, G., Chaudhuri, S. and Dutta, D. (2010). The present perspective of astaxanthin with reference to biosynthesis and pharmacological importance. World J. Microbiol. Biotechnol., 26(11), 1925-1939.

Kurashige, M., Okimasu, E., Inoue, M. and Utsumi, K. (1990). Inhibition of oxidative injury of biological membranes by astaxanthin. Physiol. Chem. Phys. Med. NMR, 22, 27-38.

Lorenz, R.T. and Cysewski, G.R. (2000). Commercial potential for Haematococcus microalgae as a natural source of astaxanthin. Trends Biotechnol., 18, 160-167.

Martin, G., Mark, E.H. and Miguel, O. (2003). Haematococcus astaxanthin: applications for human health and nutrition. Trends Biotechnol., 21, 210-216.

Meor Mohd Affandi, M.M.R., Julianto, T. and Majeed, A.B.A. (2011). Development and stability evaluation of astaxanthin nanoemulsion. Asian J. Pharm. Clin. Res., 4, 142-148.

Meor Mohd Affandi, M.M.R., Abdullah, A., Julianto, T. and Majeed, A.B.A. (2012). Development of simple high performance liquid chromatographic method for the determination of astaxanthin in human plasma. Food Sci. Technol. Res., 107-113.

Odeberg, J.M., Lignell, A., Pettersson, A. and Hoglund, P. (2003). Oral bioavailability of the antioxidant astaxanthin in humans is 
enhanced by incorporation of lipid based formulations. Eur. J. Pharm. Sci., 19, 299-304.

Olaizola, M. and Huntly, M.E. (2003). Recent advances in commercial production of astaxanthin from microalgae. In Biomaterials and bioprocessing. Oxford, Science Publisher, pp. 102-116.

Olson, J.A. (1994). Absorption, transport, and metabolism of carotenoids in humans - carotenoids. Pure Appl. Chem., 66, 10111116.

Osterlie, M., Bjerkeng, B. and Liaaen-Jensen, S. (2000). Plasma appearance and distribution of astaxanthin $\mathrm{E} / \mathrm{Z}$ and $\mathrm{R} / \mathrm{S}$ isomers in plasma lipoproteins of men after single dose administration of astaxanthin. J. Nutr. Biochem., 11, 482-490.

Shimidzu, N. (1996). Carotenoids as singlet oxygen quenchers in marine organism. Fisheries Sci., 62, 134-137.

Tan, C.P. and Nakajima, M. (2005). $\beta$-Carotene nanodispersions: Preparation, characterization and stability evaluation. Food Chem., 92, 661-671.

Yuan, Y., Gao, Y., Zhao, J. and Mao, L. (2008). Characterization and stability evaluation of $\beta$-carotene nanoemulsions prepared by high pressure homogenization under various emulsifying conditions. Food Res. Int., 41, 61-68. 